\title{
CJEM Debate Series: \#ChoosingWisely - The Choosing Wisely campaign will not impact physician behaviour and choices - CORRIGENDUM
}

Paul Atkinson; Eddy Lang; Meaghan Mackenzie; Rashi Hiranandani; Rebecca Lys; Megan Laupacis; Heather Murray

doi:10.1017/cem.2017.402

In the original publication of this article, Rashi Hiranandani's name was misspelled.

The authors regret this error. The original version has been updated.

\section{REFERENCE}

Atkinson P, Lang E, Mackenzie M, Hiranandani R, Lys R, Laupacis M, Murray H, CJEM Debate Series: \#ChoosingWisely - The Choosing Wisely campaign will not impact physician behaviour and choices. CFEM 2018;20(2):170-5. doi: $\underline{10.1017 / \mathrm{cem} .2017 .402 .}$ 